\title{
Quantitative Analysis of Pyridine Nucleotides in Red Blood Cells: A Single-Step Extraction Procedure
}

\author{
Barry J. Sander, Fred J. Oelshlegel, Jr. ${ }^{1}$, and George J. Brewer \\ Department of Human Genetics, University of Michigan Medical School, \\ Ann Arbor, Michigan 48104
}

Received June 4, 1975; accepted October 10, 1975

\begin{abstract}
Quantitative analysis of red cell pyridine nucleotides has been unreliable in the past because of technical problems in extracting them in the presence of hemoglobin. A simple alcoholic extraction procedure for analysis of pyridine nucleotides in red blood cells is described in this paper. Pyridine nucleotides extracted in the presence of hemoglobin in solution show recoveries of NADH, NAD, and NADP averaging over $70 \%$, while recoveries of $\mathrm{NADPH}$ were about $60 \%$. In order to show that these techniques could detect actual intracellular differences in nucleotides inside red cells, two experiments were performed in which the ratios of the nucleotides would be predictably altered. Intact cells incubated in the presence of methylene blue show a decrease in the NADPH/NADP ratio, and intact cells incubated in the presence of hydrazine and lactate show an increase in the NADH/ NAD ratio. The changes in pyridine nucleotide ratios in these experiments are in the expected direction and were easily detected. Levels of pyridine nucleotides in red blood cells of normal human adults are also presented.
\end{abstract}

The pyridine nucleotides have important roles both in maintaining the redox state of the red blood cell and as cofactors in red cell glycolysis. It is useful to be able to measure the levels of the pyridine nucleotides in the red cell along with the red cell's glycolytic intermediates in order to assess both normal and abnormal cell metabolism. Quantitative analysis of red cell pyridine nucleotides has been very difficult, however, because of technical problems in extracting these nucleotides in the presence of hemoglobin. Extraction procedures normally used for other glycolytic intermediates cannot be used because reduced nucleotides are unstable in acid, and oxidized nucleotides are unstable in alkali. The work of Burch et al. (1) is the most definitive study of these technical problems. These workers have demonstrated that acid extraction of pyridine nucleotides in the presence of hemoglobin is fraught with error due to the conversion of reduced nucleotides to oxidized forms. (We have confirmed this in our laboratory and have found that, in the presence of hemoglobin, an equimolar solution of oxidized and reduced pyridine nucleotides extracted

${ }^{1}$ Present address: Department of Preventive Medicine, University of Mississippi Medical Center, Jackson, Mississippi 39216. 
in $0.6 \mathrm{~N}$ perchloric acid yielded $163 \% \mathrm{NAD}^{2}$ and $158 \%$ NADP (expressed as a percent of amounts added). A solution of only NADH extracted under the same conditions yielded NAD equal to $76 \%$ of the added NADH.) Burch et al. (1) have implicated a short-lived denaturization product of hemoglobin as a catalyst in the oxidation of reduced pyridine nucleotides.

Researchers presently utilizing the Burch et al. (1) extraction procedures measure NAD and NADH in ratios which differ greatly from that expected from the GA-3-PD and LDH reaction equilibria in the red cell (2). In this communication, we wish to describe an extraction procedure for pyridine nucleotides which circumvents the problem of oxidation of reduced pyridine nucleotides caused by acid extraction of hemoglobin. The extraction medium remains alkaline throughout the extraction, yet is close enough to neutrality so as not to destroy the oxidized pyridine nucleotides. This procedure has several advantages over other extraction procedures. Our procedure is accurate and reproducible as is shown by recovery experiments done in the presence of hemoglobin, and our red cell levels are close to those expected from GA-3-PD and LDH reaction equilibria. When a solution of reduced pyridine nucleotides (NADH and NADPH) is extracted in the presence of hemoglobin, there is little conversion of these nucleotides to their oxidized states $(5 \%)$. There is only one extract, and from this one can obtain reasonable recoveries of all of the pyridine nucleotides (NAD, NADH, NADP, NADPH). The extract can be assayed for pyridine nucleotides using fluorometric techniques, without having to neutralize, acidify, or use enzyme cycling techniques.

\section{MATERIALS}

Pyrophosphate, pyruvate, ethylenediamine tetraacetic acid, NAD, NADH, NADP, NADPH, glucose-6-phosphate (all of the preceding are sodium salts), Tris, imidazole, lactic acid, hydrazine sulfate, $\alpha$-ketoglutarate (potassium salt), alcohol dehydrogenase, and lactate dehydrogenase were all obtained from the Sigma Chemical Co. (St. Louis, Mo.). We obtained glucose-6-phosphate dehydrogenase and glutamate dehydrogenase from the Boehringer-Mannheim Corp. (Mannheim, Germany), $\mathrm{K}_{2} \mathrm{HPO}_{4}, \mathrm{MgCl}_{2}$, and $\mathrm{ZnCl}_{2}$ from Matheson, Coleman, and Bell (Norwood, Ohio), glycine from Nutritional Biochemicals (Cleveland, Ohio), $\mathrm{KCl}$ from Baker Chemical Co. (Phillipsburg, N.J.), and methylene blue from Mallinckrodt (St. Louis, Mo.).

\footnotetext{
${ }^{2}$ Abbreviations used: NAD, nicotinamide adenine dinucleotide; NADH, nicotinamide adenine dinucleotide, reduced form; NADP, nicotinamide adenine dinucleotide phosphate; NADPH, nicotinamide adenine dinucleotide phosphate, reduced form; GA-3-PD, glyceraldehyde-3-phosphate dehydrogenase; LDH. lactate dehydrogenase.
} 


\section{METHODS}

For the red cell extraction procedure, $6.0 \mathrm{ml}$ of absolute ethanol and 2.0 $\mathrm{ml}$ of $0.2 \mathrm{M} \mathrm{K}_{2} \mathrm{HPO}_{4}$, pH 9.0, were pipetted into a 125 -ml Erlenmeyer flask. A marble was placed over the mouth of the flask in order to minimize loss by evaporation while heating. The flask was heated just to the boiling point, and $2.0 \mathrm{ml}$ of a freshly drawn blood sample (heparinized Vacutainers B.D., Rutherford, N.J.) were quickly pipetted into the alcoholic mixture. The mixture was reboiled $(2 \mathrm{sec})$ while shaking. The flask was then submerged in an ice-water bath, and $2.0 \mathrm{ml}$ of $0.1 \mathrm{M} \mathrm{ZnCl}_{2}$ were pipetted into the flask, again with shaking. The flask was allowed to sit at $0^{\circ} \mathrm{C}$ for at least $20 \mathrm{~min}$ to enhance protein precipitation, after which the mixture was centrifuged for $15 \mathrm{~min}$ at $48,000 \mathrm{~g}, 2^{\circ} \mathrm{C}$ in a Sorval RC2-B refrigerated centrifuge. The supernatant was decanted and kept at $0^{\circ} \mathrm{C}$ until assay. The supernatant had an approximate $\mathrm{pH}$ of 7.5 and retained some protein in solution. This protein precipitated as the extract sat on ice during the assays. When the extract clouded, no further assays were done until a 5-min centrifugation at $48,000 \mathrm{~g}$ to rid the extract of protein. This was necessary because the precipitating protein interfered with fluorescence in the cuvette and gave faulty recoveries.

All assays were carried out on an Eppendorf (Brinkmann) Fluorometer Model $1101 \mathrm{M}$ (primary filter $\mathrm{Hg} \mathrm{313-366} \mathrm{nm,} \mathrm{secondary} \mathrm{filter} \mathrm{400-3000}$ $\mathrm{nm}$ ) with a Brinkman type recorder.

The assays for the pyridine nucleotides were essentially those of Segal et al. (3). In each assay $1.0 \mathrm{ml}$ of the alcoholic extract was added to a cuvette containing $2.0 \mathrm{ml}$ buffer (see below), sensitivity ranges were selected for both fluorometer and recorder, baselines were allowed to stabilize, and then appropriate enzymes were added to initiate the reaction. Enzyme concentrations have been chosen in such a way as to minimize blank change and complete the reaction in less than $10 \mathrm{~min}$.

In the NAD assay, five units of alcohol dehydrogenase in $2 \mu \mathrm{H}_{2} \mathrm{O}$ were added to cuvettes containing $1.0 \mathrm{ml}$ of extract and $2.0 \mathrm{ml}$ of a solution of $30 \mathrm{~mm}$ tetrasodium pyrophosphate and $14.25 \%$ ethanol to produce the reaction.

In the NADP assay, 0.04 units of glucose-6-phosphate dehydrogenase in $2 \mu \mathrm{H}_{2} \mathrm{O}$ were added to cuvettes containing $1.0 \mathrm{ml}$ of extract and $2.0 \mathrm{ml}$ of a solution of $120 \mathrm{~mm}$ Tris, $0.15 \mathrm{mM} \mathrm{MgCl}_{2}, 1.5 \mathrm{~mm}$ glucose-6-phosphate, $\mathrm{pH} 7.0$, to produce the reaction.

In the NADH assay, 0.20 units of lactate dehydrogenase in $5 \mu \mathrm{H}_{2} \mathrm{O}$ were added to cuvettes containing $1.0 \mathrm{ml}$ of extract and $2.0 \mathrm{ml}$ of a solution of $75 \mathrm{~mm}$ imidazole (low fluorescence blank), $7.5 \mathrm{~mm} \mathrm{MgCl}_{2}$,

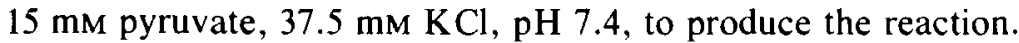

In the NADPH assay, 0.50 units of glutamate dehydrogenase in $10 \mu \mathrm{H}_{2} \mathrm{O}$ were added to cuvettes containing $1.0 \mathrm{ml}$ of extract and $2.0 \mathrm{ml}$ 
of a solution of $75 \mathrm{~mm}$ imidazole, $7.5 \mathrm{mM} \mathrm{MgCl}_{2}, 7.5 \mathrm{mM} \alpha$-ketoglutarate,

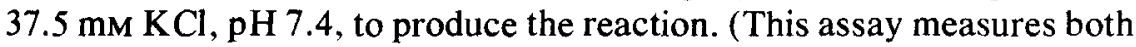
NADPH and NADH. The NADH obtained in the above assay must be subtracted from this in order to obtain NADPH.

\section{RESULTS}

\section{Recovery Experiments}

We wished to conduct our recovery experiments (Table 1) under conditions closely approximating red cell physiological conditions, so we carried them out in the presence of hemolysate. For the data in Table 1, to the hot alcoholic mixture $\left(15.0 \mathrm{ml}\right.$ ethanol, and $\left.5.0 \mathrm{ml} \mathrm{K}_{2} \mathrm{HPO}_{4}, \mathrm{pH} 9.0\right)$ were added: (1) $1.0 \mathrm{ml}$ of the pyridine nucleotide solution which contained 100 $\mu_{\mathrm{M}}$ concentrations each of NAD, NADH, NADP, and NADPH; (2) $2.0 \mathrm{ml}$ of a packed red cell freeze-thaw lysate containing $35 \mathrm{~g} \%$ hemoglobin; and (3) $2.0 \mathrm{ml}$ of plasma. In this way the pyridine nucleotides were in intimate contact with the denaturing hemoglobin and red cell contents first, and the denaturing plasma proteins second. The extraction was completed according to the normal procedure. (From the addition of the pyridine nucleotide solution to the submerging of the flask in ice-water, less than 1 min elapsed.) Recoveries of NAD, NADP, and NADH under these conditions averaged over $70 \%$ while recoveries of NADPH were somewhat lower (Table 1).

One recovery experiment in which the reduced pyridine nucleotides were varied in concentration $(25,50$, and $100 \mu \mathrm{M})$, and extracted in this same manner, showed similar percent recovery of NADH and NADPH at all concentrations.

\section{Perturbation Experiments}

Two experiments were carried out in order to test the ability of these procedures to detect changes in the concentration of the pyridine nucleotides in intact red blood cells.

(1) Lactate hydrazine incubation experiment. The equilibrium of the lactate dehydrogenase (LDH) step in red cell glycolysis can theoretically

\section{TABLE 1}

Recovery of Pyridine Nucleotides in the Presence of Hemoglobin ${ }^{a}$

\begin{tabular}{ll}
\hline NAD & $78.2 \pm 2.4 \%$ \\
NADH & $74.8 \pm 3.0 \%$ \\
NADP & $71.0 \pm 2.6 \%$ \\
NADPH & $58.2 \pm 4.8 \%$ \\
\hline
\end{tabular}

a Mean and standard deviations of four experiments. 
be shifted towards NADH by incubating with lactate and hydrazine. Hydrazine complexes with pyruvate, and this combined with increased lactate should change the NADH/NAD ratio in favor of more NADH.

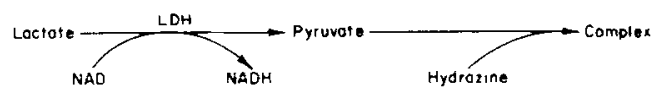

Two milliliters of a freshly drawn blood sample from a normal adult were extracted for pyridine nucleotide analysis. Five milliliters of the same blood were incubated at $37^{\circ} \mathrm{C}$ in air after $2.0 \mathrm{ml}$ of a solution containing $50 \mathrm{~mm}$ lactic acid, $33 \mathrm{~mm}$ glycine, $13 \mathrm{~mm}$ hydrazine sulfate, and 1.3 $\mathrm{mM}$ ethylenediamine tetraacetic acid, $\mathrm{pH} 7.7$, were added giving a blood $\mathrm{pH}$ of 7.36. After $10 \mathrm{~min}$ of incubation, $2 \mathrm{ml}$ were extracted for pyridine nucleotide analysis, and corrections were made for dilution by measuring hemoglobin on both aliquots. (An extraction of the hydrazine and the pyridine nucleotide solutions in the absence of red cells was performed in order to eliminate the possibility of artifacts being introduced by hydrazine at extremes of temperature. There was no reduction of NAD to NADH.) As expected, marked differences in the nucleotide concentrations were seen (Table 2A).

(2) Methylene blue incubation experiment. We expect pyridine nucleotide analysis of red blood cells incubated with methylene blue to show oxidation of NADPH to NADP. Two milliliters of freshly drawn blood from a normal Caucasian adult were extracted for pyridine nucleotide analysis. An aliquot of the same blood was incubated at $37^{\circ} \mathrm{C}$ in air with a final concentration of $0.04 \mathrm{~mm}$ methylene blue. After $10 \mathrm{~min}, 2.0 \mathrm{ml}$ were extracted for pyridine nucleotide analysis. (An extraction of the methylene blue and the pyridine nucleotide solutions in the absence of red cells was performed in order to eliminate the possibility of artifacts being introduced by methylene blue at extremes of temperature. There was no

TABLE 2

\begin{tabular}{cc}
\hline $\begin{array}{c}\text { Before incubation } \\
(\mu \mathrm{mol} / \mathrm{g} \mathrm{Hb})\end{array}$ & $\begin{array}{c}\text { After incubation } \\
(\mu \mathrm{mol} / \mathrm{g} \mathrm{Hb})\end{array}$ \\
\hline
\end{tabular}

(A) Lactate-hydrazine incubation experiment

$\begin{array}{lll}\text { NADH } & 0.002 & 0.049 \\ \text { NAD } & 0.199 & 0.154 \\ \text { NADH/NAD } & 0.010 & 0.318\end{array}$

(B) Methylene blue incubation experiment

NADPH 
TABLE 3

Pyridine Nucleotide Levels in Adult Normal Caucasian Males

Mean \pm standard deviation ( $\mu \mathrm{mol} / \mathrm{g} \mathrm{Hb}$ )

$\begin{array}{ll}\text { NAD } & 0.183 \pm 0.026 \\ \text { NADH } & 0.005 \pm 0.001 \\ \text { NADP } & 0.028 \pm 0.005 \\ \text { NADPH } & 0.060 \pm 0.008\end{array}$

oxidation of NADPH to NADP.) Again, the extraction and assay procedures reflect the effects of the perturbing agent (Table 2B).

\section{Normal Human Levels}

Table 3 presents the average pyridine nucleotide values observed in three normal Caucasian males.

\section{Replicability and Storage}

Two extracts were separately prepared from one blood sample. This was done for samples from three different people. The standard deviations were calculated by averaging the coefficients of variation $(\sigma / \bar{x})$ determined from the three pairs of replicates. The results are: NAD, $\pm 5.2 \%$; $\mathrm{NADH}, \pm 19 \%$; NADP, $\pm 4.4 \%$; NADPH, $\pm 4.6 \%$. These results indicate the standard deviation as a percentage of the mean and represent the error introduced by the extraction procedure.

Table 4 presents blood samples taken from one person at different times. The results indicatc reasonable consistency in one individual over time.

We examined the effect on nucleotide levels of variation in time in precipitating the blood sample by precipitating one aliquot immediately,

TABLE 4

Variation in Pyridine Nucleotide Levels of a Single Subject

\begin{tabular}{lccc}
\hline & \multicolumn{3}{c}{$(\mu \mathrm{mol} / \mathrm{g} \mathrm{Hb})$} \\
\cline { 2 - 4 } & $\mathrm{CK}$ & $\mathrm{CK}$ & $\mathrm{CK}$ \\
& $12-4-74$ & $2-10-75$ & $2-24-75$ \\
\hline NAD & 0.192 & 0.171 & 0.192 \\
NADH & 0.006 & 0.005 & 0.004 \\
NADP & 0.022 & 0.028 & 0.025 \\
NADPH & 0.065 & 0.066 & 0.068 \\
\hline
\end{tabular}


while a second aliquot was incubated at $37^{\circ} \mathrm{C}$ for $5 \mathrm{~min}$ and then precipitated. No differences were found (data not shown).

Table 5 presents data on storageability of the alcoholic extract. A blood sample was extracted in duplicate, and assayed on the same day. The extracts were frozen at $-70^{\circ} \mathrm{C}$ and assayed on Days 2 and 64 . The results show a decrease in NADP and NADPH and an increase in NAD by Day 64.

\section{DISCUSSION}

The recoveries we are presently achieving represent a significant advance in pyridine nucleotide extraction in terms of reasonable yields, reproducibility, and detection of predicted changes during incubations. We would have liked to have developed methods yielding $100 \%$ recovery of all pyridine nucleotides in the presence of hemoglobin. Nevertheless, our procedures result in reproducible and quantitative recoveries.

Burch et al. (1) went to great lengths to show that hemoglobin was responsible for oxidation of reduced pyridine nucleotides, and then did a recovery in which the pyridine nucleotides were added to tissue homogenates which had already been extracted rather than adding the nucleotides to the proteins and tissue as they were denaturing. Reinauer and Bruns (4) did recovery experiments in which pyridine nucleotides were added to intact cells as they were being extracted. The pyridine nucleotides were not in intimate contact with the hemoglobin as it was denaturing but were outside the cell. Presumably, the difference in recovery of pyridine nucleotides in our experiments (70\%) and those of Reinauer and Bruns $(90 \%)$ are due to the fact that nucleotides were added to whole cells in the Reinauer and Bruns recovery experiments, while we added hemoglobin in solution to an extraction medium which had been supplemented with pyridine nucleotides, thereby exposing the nucleotides to the hemoglobin as it denatured.

TABLE 5

Storage of the Alcoholic Extract ${ }^{a}$

\begin{tabular}{lccc}
\hline & \multicolumn{3}{c}{ Days stored } \\
\cline { 2 - 4 } & 0 & 2 & 64 \\
\hline NAD & 0.163 & 0.163 & 0.177 \\
NADH & 0.005 & 0.005 & 0.005 \\
NADP & 0.028 & 0.027 & 0.022 \\
NADPH & 0.062 & 0.053 & 0.055 \\
\hline
\end{tabular}

a These values represent the average of two determinations and are expressed in $\mu \mathrm{mol} / \mathrm{g} \mathrm{Hb}$. 
TABLE 6

Pyridine Nucleotide Content of Freshly Drawn Erythrocytes ${ }^{a}$

\begin{tabular}{|c|c|c|c|c|}
\hline & NAD & $\mathrm{NADH}$ & NADP & NADPH \\
\hline Gross et al. (5) & 0.198 & 0.149 & 0.115 & 0.086 \\
\hline $\begin{array}{l}\text { Omachi et al. }(6)^{b} \text { using Burch et al. (1) } \\
\text { extraction procedures }\end{array}$ & 0.276 & 0.159 & 0.003 & 0.135 \\
\hline $\begin{array}{l}\text { Omachi et al. }(6)^{b} \text { using Lowry et al. (7) } \\
\text { extraction procedures }\end{array}$ & 0.228 & 0.111 & 0.111 & 0.135 \\
\hline Marshall and Omachi (4) & 0.186 & 0.081 & - & - \\
\hline Reinauer and Bruns $(3)^{c}$ & - & 0.009 & - & 0.066 \\
\hline Present study & 0.183 & 0.005 & 0.028 & 0.060 \\
\hline
\end{tabular}

${ }^{a} \mu \mathrm{mol} / \mathrm{g} \mathrm{Hb}$.

${ }^{b}$ Data expressed as $\mathrm{nmol} / \mathrm{ml}$ erythrocyte have been converted to $\mu \mathrm{mol} / \mathrm{g} \mathrm{Hb}$ by assuming a mean cell hemoglobin concentration of $33.3 \mathrm{~g} \%$.

c Data expressed as $\mu \mathrm{mol} / \mathrm{ml}$ blood have been converted to $\mu \mathrm{mol} / \mathrm{g} \mathrm{Hb}$ by assuming a hemoglobin concentration of $150 \mathrm{~g} /$ liter whole blood.

A comparison of values obtained for fresh, normal human erythrocytes with other extraction procedures by other authors is presented in Table 6 . We find ourselves forced to point out the discrepancy between blood values demonstrated in this work and those found in other papers excluding Reinauer and Bruns (4) (Table 6). The red blood cell levels of reduced pyridine nucleotides obtained by our procedure and those obtained by the Reinauer and Bruns procedure are essentially the same (Table 6). However, the Reinauer and Bruns extraction procedure is only capable of extraction for reduced pyridine nucleotides because oxidized nucleotides are destroyed in the alkaline medium. Our procedures were validated by rigorous recovery experiments, and other procedures have not been so validated. (As pointed out above, Reinauer and Bruns have come the closest, and their NADH and NADPH blood values agree with ours.) Our NAD/NADH ratio agrees with that expected from the $\mathrm{LDH}$ and GA-3-PD reaction equilibria in the red cell. We conclude that the procedures described for extraction and analysis of pyridine nucleotides in the red cell represent the best techniques so far available.

\section{REFERENCES}

1. Burch, H. B., Bradley, M. E., and Lowry, O. H. (1967) J. Biol. Chem. 242, 4546-4554.

2. Marshall, W. E., and Omachi, A. (1974) Biochim. Biophys. Acta 354, 1-10.

3. Segal, G. B., Feig, S. A., Baehner, R. L., and Nathan, D. G. (1971) J. Lab. Clin, Med. 78, 969-976.

4. Reinauer, H., and Bruns, F. H. (1964) Z. Physiol. Chem. 337, 93-100.

5. Gross, R. T., Schroeder, E. A., and Gabrio, B. W. (1966) J. Clin. Invest. 45, 249-255.

6. Omachi, A., Scott, C. B., and Hegarty, H. (1969) Biochim. Biophys. Acta 184, 139-147.

7. Lowry, O. H., Passonneau, J. V., and Rock, M. K. (1961) J. Biol. Chem. 236, 27562759. 